Case Study

https://doi.org/10.20546/ijcmas.2020.907.321

\title{
Successful Management of Dystocia in Sheep Due to Fetal Causes: Two Different Rare Cases
}

\author{
Satish Nain', Satish Kumar ${ }^{2 *}$, A.F.B. Silva ${ }^{2}$, Bhartendu ${ }^{3}$ and Naveen Chahar ${ }^{4}$
}

${ }^{1}$ Department of Veterinary Gynaecology and Obstetrics, College of Veterinary and Animal Science, Bikaner, Rajasthan University of Veterinary and Animal Sciences, Bikaner, Rajasthan, India

${ }^{2}$ Faculty of Veterinary Medicine, Post-Graduate Programme of Veterinary Sciences, State University Ceará (UECE), Av. Dr. Silas Munguba, Campus of Itaperi, Fortaleza, Brazil

${ }^{3}$ Government Veterinary Hospital, Jawahar Nagar, Mahendragarh, Haryana, India ${ }^{4}$ International institute of veterinary education and research (IIVER), Rohtak, Lala Lajpat Rai University of Veterinary and Animal Sciences, Hisar, Haryana, India

*Corresponding author

A B S T R A C T

\section{Keywords}

Dystocia, Fetal arthrogryposis, Schistosomus reflexus, Sheep

Article Info

Accepted:

22 June 2020

Available Online:

10 July 2020

\section{Introduction}

Schistosomus Reflexus is generally reported in cattle (Noakes et al., 2008), but it is rarely observed in sheep (Suthar et al., 2011; Dar et al., 2015) and goats (Kumar et al., 2016; Nain et al., 2019). It is a fatal congenital anomaly, characterized by the incomplete fusion of the abdominal wall results exposure of abdominal and sometimes thoracic viscera, marked ventral curvature of the spine, limb ankylosis, positioning of the limbs adjacent to the skull and, lung and diaphragm hypoplasia (Laughton et al., 2005).

Arthrogryposis is unusual fetal causes of dystocia in small ruminants (Bokko et al., 2015). It is a congenital defect characterized 
by fixed flexion or rigidity of the one or more joints and wasting of muscles (Khodakaram et al., 2014).

\section{Case history and observations}

\section{Case 1: Dystocia due to Schistosomus Reflexus}

A full-term pregnant, third parity, non- descript ewe aged approximately 3 years was attended at the doorstep of a farmer of the Bikaner (State-Rajasthan) with the history of rupture of water bag and straining since last 11 hours.

Clinical examination revealed, normal rectal temperature $\left(102.5^{\circ} \mathrm{F}\right)$ and pulse rate. The visceral organs of the fetus were hanging out (Fig.1.A).

Fig.1 A case of SchistosomusReflexus; A- Showing visceral presentation of fetus. B- Showing ankylosed foetal limbs, ventral curvature of spine, angulated lumbar region and abdominal wall exposing abdominal viscera in a lamb
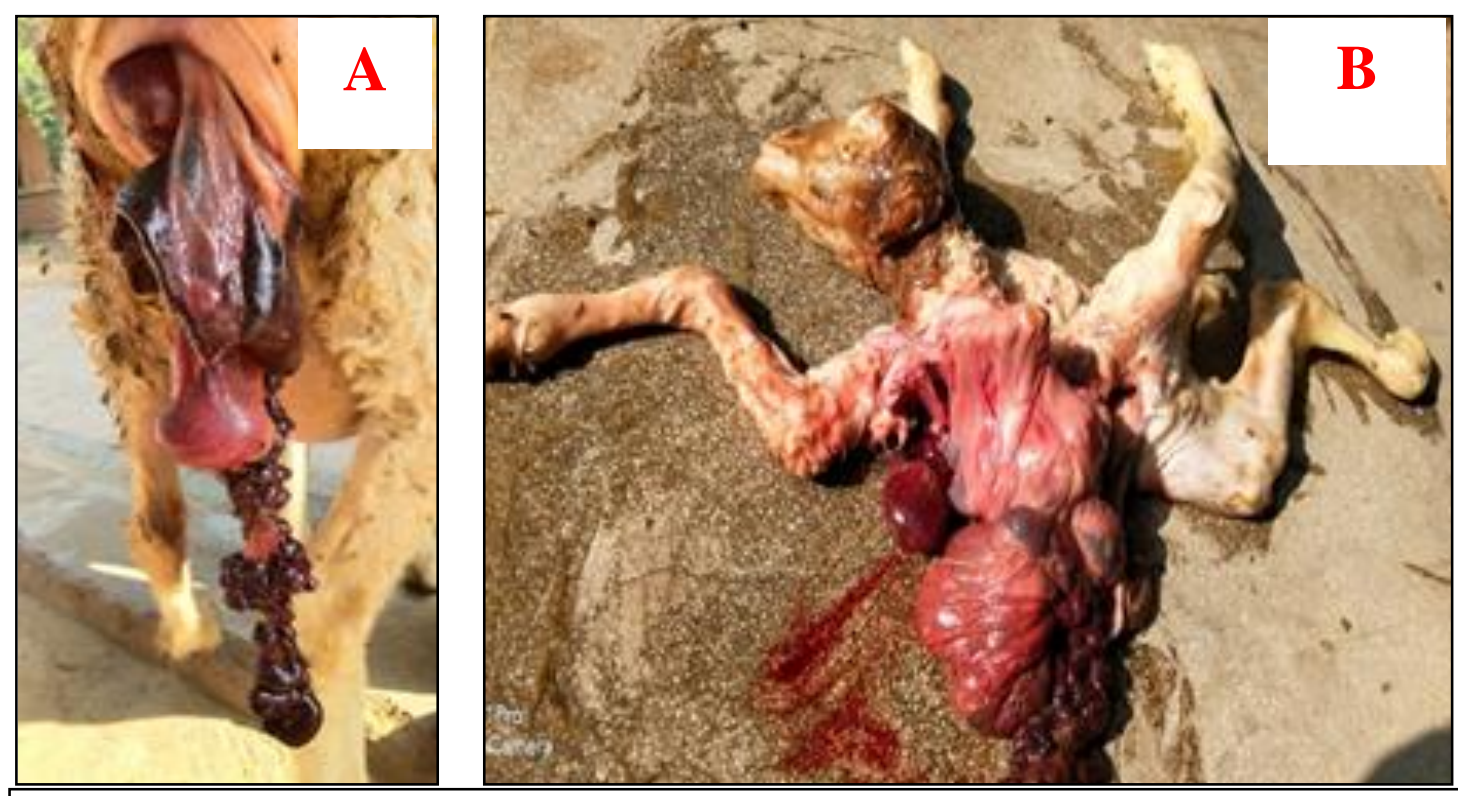

Fig.1: A case of Schistosomus Reflexus; A- Showing visceral presentation of fetus. B- Showing ankylosed foetal limbs, ventral curvature of spine, angulated lumbar region and abdominal wall exposing abdominal viscera in a lamb. 
Fig.2 A case of Fetal Arthrogryposis showing amputated head and limbs

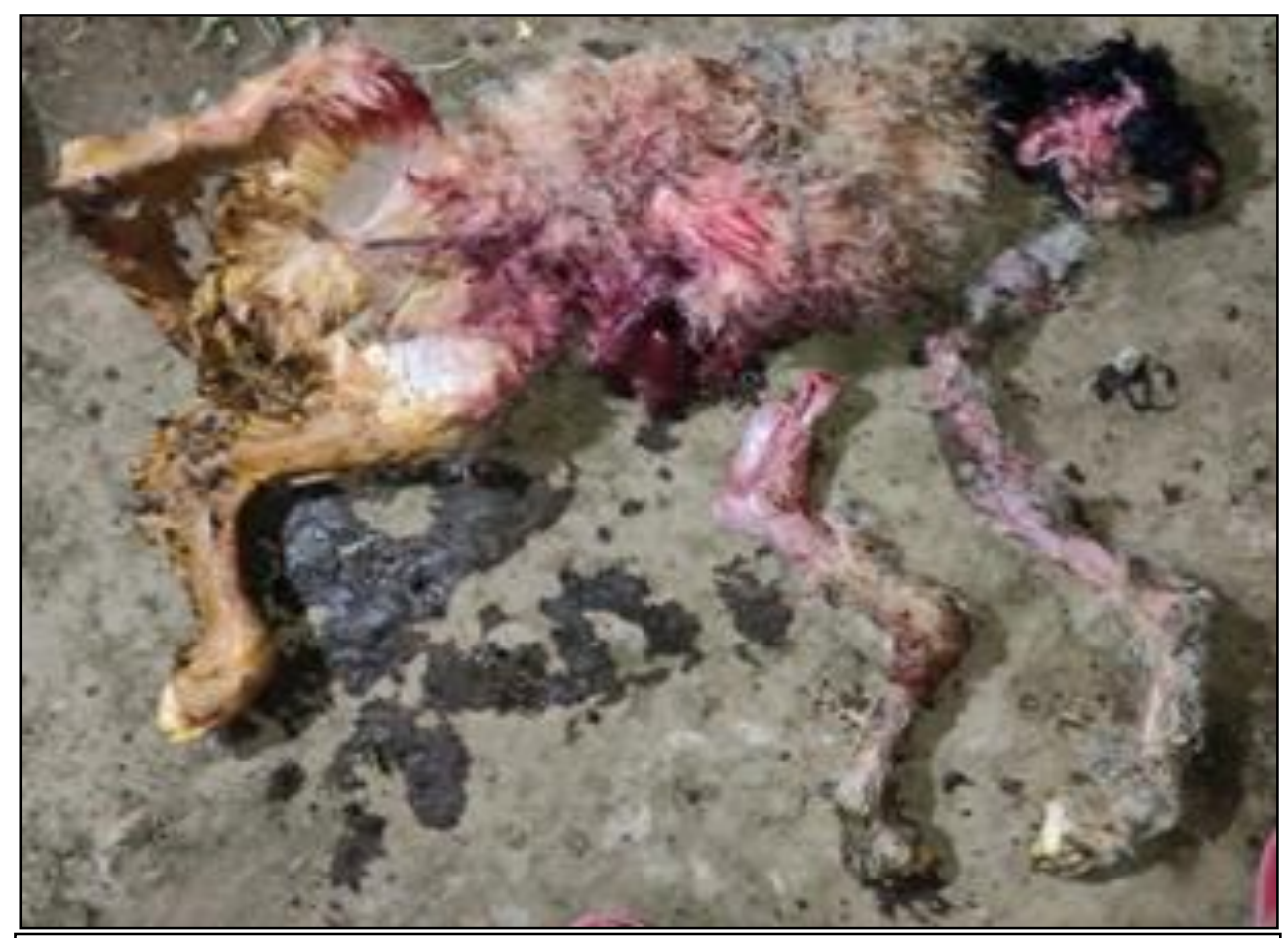

Fig.2 A case of Fetal Arthrogryposis showing amputated head and limbs.

\section{Treatment and discussion}

\section{Case.1}

The vaginal passage and uterus were thoroughly lubricated by liquid paraffin. After that, the female foetus was delivered pervaginum by mild traction with hand on the forelimbs and head along with simultaneous adjustment of the other foetal parts. Further examination revealed the absence of another fetus and laceration in the birth canal and uterus. Afterwards, Two Furea bolus were placed intra-uterine and the ewe was treated with parenteral antibiotic along with supportive therapy.

Morphologically (Fig.1.B), there were ankylosed foetal limbs, ventral curvature of spine, angulated lumbar region, abdominal wall exposing abdominal viscera, an incomplete diaphragm and hypoplastic lungs. It was diagnosed as a true case of SR. Our observations are supported by Dar et al., (2015) in sheep.

\section{Case. 2}

The vaginal passage and uterus were thoroughly lubricated by liquid paraffin. The traction attempt was unfruitful due to the stiffness of joints and suspected as fetal anomaly. First, the head of the fetus was pulled out and amputated followed by both the forelimbs one by one and finally delivered the male fetus by traction (Fig.2). Further 
examination revealed the absence of another fetus and laceration in the birth canal and uterus. Afterwards, Two Furea bolus were placed intra-uterine and the ewe was treated with parenteral antibiotic along with supportive therapy.

The case was declared as FA because all the four fetlock joints were ankylosed. Occasionally, arthrogryposis is associated with other pathological conditions such as torticollis and kyphosis (Noakes et al., 2008). In our case fetus was without other skeletal pathological conditions. These pathological conditions have been results from a viral infection of the dam during pregnancy (Noakes et al., 2008).

The ewes were normal, observed after seven days of treatment. A number of factors are responsible for congenital defects (Noakes et al., 2008).However, majority of congenital defects are reported to be related to genetic factors (mutations and chromosomal abnormalities), nutritional and infectious agents or the combination of all the listed factors (Plummer, 2004). The congenital abnormal conditions in both cases may be due to genetic factors because other ewes in the flock were normal lambing and there was not history of any disease.

\section{References}

Bokko, P.B., Adamu., Simon, S., Garleya, B. and Suleiman, 2015. Congenital orthopaedic deficiency phenotypes in sheep and goats in Sahel. Annals of Vet. and Anim. Sci., 2(4): 86-97.

Dar, M.U.D., Ahmad, F., Dar, K.H., and Athar, H. 2015. A Typical Case of True SchistosomusReflexus (SR) in a Local Ewe of Kashmir Mehraj. J. Vet. Sci. Technol., 6(4): 241. http://dx.doi:10.4172/2157-
7579.1000241.

Khodakaram-Tafti, A., Kish, F., Mohammadi, $\mathrm{G}$ and Alidadi, S. 2014. Congenital arthrogryposis associated with musculoskeletal defects in three new born goats.Iranian J. Vet. Res.,15 (2): 176-178.

Kumar, B., Yadav, D., Vandana and Saxena A. 2016. Schistosomus Reflexus in a Goat - A Case Report. Theriogenology Insight., 6(3): 119-121. http://dx.doi:10.5958/22773371.2016.00016.4.

Laughton, K.W., Fisher, K.R., Halina, W.G. and Partlow, G.D. 2005. Schistosomusre flexus syndrome: a heritable defect in ruminants. Anat. Histol. Embryol., 34(5): 312-318. https://doi.org/10.1111/j.14390264.2005.00624.x.

Nain, S., Kumar, S., Nirwan, S.S., and Chahar, N. 2019. Dystocia Due to Schistosomusreflexus in a Goat - A Case Report. Int. J. Livest. Res., 9(12):221-223. http://dx.doi.org/10.5455/ijlr.20190917 055831.

Noakes, D.E., Parkinson, T.J. and England, G.C.W. 2008. Arthur's veterinary reproduction and obstetrics. 8th Ed., Philadelphia, Elsevier.Pp. 119-143.

Plummer, P.J. 2004. Congenital Anomalies in the Sheep and Goat (Susan, L., Fubini, N. G. and Ducharme). Farm Animal Surgery, W.B. Saunders.Pp.549-552. https://doi.org/10.1016/B0-72-1690629/50024-1.

Suthar, D.N., Sharma, V.K., Dabas, V.S., and Bhoi, D.B. 2011. Per-vaginal handling of Schistosomusreflexus as a cause of dystocia in a Goat. Vet. World., 4(7):330-331.

http://dx.doi:10.5455/vetworld.4.330. 


\section{How to cite this article:}

Satish Nain, Satish Kumar, Ana Flávia Bezerra da Silva, Bhartendu andNaveen Chahar. 2020. Successful Management of Dystociain Sheep Due to Fetal Causes: Two Different Rare Cases. Int.J.Curr.Microbiol.App.Sci. 9(07): 2722-2726. doi: https://doi.org/10.20546/ijcmas.2020.907.321 